\title{
THE
}

6-9-2013

\section{Circumferential Pressure's Inhibitory Effects on Soleus H-Reflex}

James Agostinucci

University of Rhode Island, gusser@uri.edu

Follow this and additional works at: https://digitalcommons.uri.edu/pt_facpubs

Creative Commons License

(c) $(1) \Theta \Theta$

This work is licensed under a Creative Commons Attribution-Noncommercial-No Derivative Works 3.0 License.

\section{Citation/Publisher Attribution}

Agostinucci, J. (2013). Circumferential pressure's inhibitory effects on soleus H-reflex. Translational Neuroscience, 4(2), 251-259. doi: 10.2478/s13380-013-0119-0

Available at: http://dx.doi.org/10.2478/s13380-013-0119-0

This Article is brought to you for free and open access by the Physical Therapy at DigitalCommons@URI. It has been accepted for inclusion in Physical Therapy Faculty Publications by an authorized administrator of DigitalCommons@URI.For more information, please contact digitalcommons-group@uri.edu. 


\section{CIRCUMFERENTIAL PRESSURE'S INHIBITORY EFFECTS ON SOLEUS H-REFLEX}

\begin{abstract}
Background: Circumferential pressure (CP) applied to the lower leg reduces soleus motor neuron reflex excitability (MNRE); however, the mechanism of control is unknown. Aim: To investigate the effect that CP has on disynaptic reciprocal inhibition (DSRI) and on la presynaptic inhibition (IaPI) of the soleus H-reflex in healthy subjects. Methods: DSRI of soleus motoneurons and presynaptic control of soleus group la afferents were measured before, during and after CP was applied to the calf. Pressure was set to $40-45 \mathrm{mmHg}$. DSRI was evaluated by observing changes in the $\mathrm{H}$-reflex amplitude after a conditioning stimulus was applied to the common peroneal nerve. laPI was assessed using two separate protocols involving conditioning of the soleus $\mathrm{H}$-reflex: femoral nerve facilitation (FNS) (heteronymous) and D1 and D2 inhibition (homonymous). A change in DSRI and laPI was determined by comparing the $\mathrm{H}_{\text {pressure' }} \mathrm{H}_{\text {post-pressure }}$ phases to the $\mathrm{H}_{\text {pre-pressure }}$ phase of the conditioned $\mathrm{H}$-reflexes. Results: A mean $12 \%$ decrease in FNS was observed during CP $(p<0.05)$. D1 and D2 inhibition decreased slightly. CP did not affect DSRI. Conclusion: The results show that CP applied to the calf significantly increased heteronymous soleus laPI, but affected homonymous laPI less. It was concluded the CP does increase laPI of soleus motoneurons but only modestly. The change was not large enough to explain the dramatic inhibition that occurs in the (unconditioned) $\mathrm{H}$-reflex amplitude when CP is applied. Therefore, laPI is not the primary inhibitory mechanism that $\mathrm{CP}$ uses to lower MNRE.
\end{abstract}

\begin{abstract}
Keywords - Circumferential pressure $\cdot \mathrm{H}$-reflex $\cdot$ Soleus muscle $\cdot$ Presynaptic inhibition - Disynaptic reciprocal inhibition - Motoneuron reflex excitability
\end{abstract}

(c) Versita Sp. z o.o.
James Agostinucci*

Physical Therapy Department University of Rhode Island,

Kingston, RI 02881, USA

\section{Background}

Circumferential pressure (CP) application and its effects on muscle activity in both the upper and lower limbs has been extensively studied [1-8]. Initial investigations examined the effect $\mathrm{CP}$ had on soleus monosynaptic reflexes in subjects without neurological deficits and compared them to subjects with cerebral vascular accidents [2,6]. A significant decrease in the soleus H-reflex amplitude and the soleus stretch reflex occurred throughout the pressure application. In a related study involving subjects with complete traumatic spinal cord injuries $(\mathrm{SCl}), \mathrm{CP}$ around the calf resulted in a similar soleus $\mathrm{H}$-reflex inhibition [7]. From these results it was suggested that the mechanism responsible for the decrease in $\mathrm{H}$-reflex amplitude was spinal in origin [7].

Many spinal cord mechanisms may account for the decrease in H-reflex amplitudes during pressure application [1-5,9-12]. Tissue ischemia and decreases in nerve conduction velocity were shown not to be involved $[5,6]$. Investigations on presynaptic inhibition of la afferents have not been formally conducted however, results from an investigation on F-waves suggest that it may have a role [1].

Studies have described a spinal cord control system that may be partly mediated through a la presynaptic inhibitory mechanism [13-20]. Hultborn et al. and Guissard et al. observed soleus $\mathrm{H}$-reflex amplitude depression after passive dorsiflexion of the ankle and hypothesized the inhibition was the result of la afferent activation [15,21]. Other investigators described $\mathrm{H}$-reflex inhibition evoked by $\mathrm{la}_{\text {, }}$ group II and Ib afferents after muscle contraction $[13,16]$. Cutaneous inputs have also been shown to effect transmission in presynaptic inhibitory pathways [22-24]. It is therefore hypothesized that the decrease in motoneuron reflex excitability (MNRE) observed during CP may use a similar mechanism.

Movement, the fundamental component of behavior, is produced when skeletal muscles contract and relax in a regulated manner. Every movement, no matter how simple, is controlled by the precise firing pattern of motoneurons populations within the motoneuron pool (excluding the contributions from muscle's viscoelastic properties). The processes that influence motoneuron behavior (excitability) therefore are important. This is especially true for clinicians who are continually looking for ways to intervene with the motor system to treat neuromuscular disorders.

The purpose of this investigation was to determine the effect that $\mathrm{CP}$ has on pre-synaptic inhibition of the soleus H-reflex in healthy subjects. Disynaptic reciprocal inhibition (DSRI) was also assessed to determine if $\mathrm{CP}$ had any affect on the la inhibitory interneuron exerted at a postsynaptic level. It was hypothesized that $\mathrm{CP}$ will cause a decrease in $\mathrm{H}$-reflex amplitude mediated through a presynaptic inhibitory mechanism. The results of this study will increase our understanding of the physiological mechanisms that regulate muscle

*E-mail:gusser@uri.edu 
activity and may also provide evidence to the extent in which sensory afferents affect the excitability of the lower limb's spinal reflex arc.

\section{Subjects and methods}

\section{Subjects}

Thirty-eight subjects (26 women, 12 men) volunteered for this study. The subjects had no history of neurological disease or lower extremity musculoskeletal disorders, and ranged in age from 19 to 65 years old (mean=30.3, SD=10.0). Subjects were asked to refrain from caffeine, aspirin, alcohol, and exercise 12 hours prior to data acquisition as these factors have been shown to alter MNRE [25]. All subjects signed informed consent forms approved by the University of Rhode Island Institutional Review Board before participating in this study.

\section{Electromyography (EMG)}

To prepare for EMG electrode placement the skin of the subject's dominant lower limb was shaved and cleaned with alcohol. Coupling gel was used on all surface electrodes to ensure proper conductance. Two $10 \mathrm{~mm}$ disc-recording electrodes were placed $3 \mathrm{~cm}$ apart on the posterior lower leg, inferior to the gastrocnemius muscle belly, and in alignment with the Achilles tendon. Two more sets of $10 \mathrm{~mm}$ disc recording electrodes were placed $3 \mathrm{~cm}$ apart on the skin over the tibialis anterior (TA) and vastus lateralis muscle bellies to monitor their activity during the study. A $5 \times 5 \mathrm{~cm}$ metal plate acted as the ground and was fixed to the anterior lateral calf, between the fibular head and lateral malleolus. EMG activity was amplified 1000x and recorded using a bandwidth of $10-10,000 \mathrm{~Hz}$. Data was digitized at a sample frequency of $10 \mathrm{~K}$ using the Powerlab ADInstruments Chart 4 Windows Data Acquisition and Analysis software and was stored on a computer's hard drive for future analysis. The EMG's amplifier had an input impedance of $1 \mathrm{M} \Omega$ ( $<47 \mathrm{pf})$, a common-mode rejection ratio of $96 \mathrm{~dB}$ at $50 \mathrm{~Hz}$ and a signal to noise ratio of $<1 \mu \mathrm{V}$ r.m.s. (root mean sqare of voltage amplitude).

\section{Soleus H-reflex}

Surface electrodes were used for both stimulation of the tibial nerve and recording
H-reflex data. The H-reflex was elicited by a $2.5 \mathrm{~cm}$ monopolar stimulating ball electrode placed on the skin over the tibial nerve in the popliteal fossa. A $10 \times 10 \mathrm{~cm}$ sponge reference electrode was fixed to the distal anterior thigh.

The H-reflex was evoked using a rectangular $1 \mathrm{~ms}$ pulse at $0.17 \mathrm{~Hz}$ (1 pulse every 6 seconds). The size of the maximal motor response $\left(M_{\max }\right)$ and the maximal $\mathrm{H}$-reflex $\left(\mathrm{H}_{\max }\right)$ were measured at the beginning and randomly throughout the experiment. Three criteria were used to determine proper electrode placement: 1) the H-reflex was evoked at a lower intensity than the soleus M-wave, 2) the least amount of intensity was required to elicit a maximum $\mathrm{H}$-reflex and 3 ) the soleus $\mathrm{M}$-wave and $\mathrm{H}$-reflex displayed a similar wave configuration. The stimulus strength was then adjusted to give an unconditioned $\mathrm{H}$-reflex that also evoked a small $\mathrm{M}$-wave and this $\mathrm{H}$-reflex was used as the experimental control $\left(H_{\text {unconditioned }}\right)[26,27]$. The $\mathrm{H}$-unconditioned reflex was approximately $25 \% \mathrm{M}_{\max } . \mathrm{H}_{\text {unconditioned }}$ was randomly monitored throughout the experiment. If a deviation in amplitude occurred ( \pm 1 SD), $H_{4}$ was readjusted back to initial baseline values $\left(\mathrm{H}_{\text {baseline }}\right)[28]$

\section{Pressure}

A $16-21 \mathrm{~cm}$ air splint was applied to the lower leg depending upon leg length proximal to the recording electrodes and distal to the fibular head. This location allowed room for the conditioning electrode to be placed on the skin over the Common Peroneal Nerve (CPN). Caution was also taken not to compress the CPN by the air- splint. Prior to starting the experiment the air splint was inflated and then passively deflated. This procedure allowed the pressure cuff to conform to the subject's leg and minimized recording electrode displacement during data acquisition. During the pressure phase of the experiment, the air splint was inflated to $40.0-45.0 \mathrm{mmHg}$ with the aid of a pressure transducer that monitored backflow from the splint. To decrease the chance of ischemia:

1. The subject's blood pressure was taken before the beginning of data recording. If diastolic pressure was below $45 \mathrm{mmHg}$, the experiment was terminated.
2. Skin color distal to the splint was closely monitored during the pressure phase of the experiment.

3. Pressure values were continually monitored and adjusted during the experiment to maintain pressures that remained within a $40-$ $45 \mathrm{mmHg}$ window.

4. M-waves were monitored throughout the experiment to ensure reflex configuration did not change.

\section{Design}

The subjects were seated comfortably in a reclined chair with their dominant lower extremity positioned in $60^{\circ}$ of hip flexion, $20^{\circ}$ of knee flexion, and $20^{\circ}$ of ankle plantar flexion. The subject's ankle was placed in an adjustable ankle rest and a moveable footrest supported the foot. To diminish any descending influence on spinal motoneurons during the experiment, subjects were instructed to remain still and quiet during testing. In addition, EMG activity from soleus, tibialis anterior and quadriceps muscles were monitored to assure no ongoing muscle activity occurred during the experiment. Figure 1 illustrates the general experimental setup.

The experiment consisted of three-test phases: pre-pressure, pressure, and postpressure. Within each phase conditioned and unconditioned reflexes were elicited. Unconditioned $\mathrm{H}$-reflexes were randomly elicited throughout the experiments to maintain consistency within the experiment. Any change in its amplitude resulted in immediate adjustment of $\mathrm{H}_{\text {unconditioned }}$ back to $\mathrm{H}_{\text {baseline }}$

The pre-pressure phase consisted of eliciting and recording $\mathrm{H}_{\text {conditioned }}$ reflexes. The air splint was then inflated and maintained at the desired pressure. The increase in pressure caused $\mathrm{H}_{\text {unconditioned }}$ to decrease substantially in every subject. It was therefore necessary to readjust $\mathrm{H}_{\text {unconditioned }}$ back to $\mathrm{H}_{\text {baseline }}$. After one minute of inflation, a second set of $\mathrm{H}_{\text {conditioned }}$ reflexes were elicited and recorded. The air splint was then passively deflated and $\mathrm{H}_{\text {unconditioned }}$ was again readjusted back to $H_{\text {baseline. }}$ After a one-minute delay, another post-pressure $\mathrm{H}_{\text {conditioned }}$ reflex set of recordings were taken. 
Experimental techniques used to assess inhibition

Presynaptic inhibition was examined using two separate protocols: 1) the technique of heteronymous la facilitation of the femoral nerve (FN) terminating on the soleus motor neurons described by Hultborn [15] and 2) common peroneal nerve (CPN) stimulation (D1 and D2 inhibition) described by LundbyeJensen and Nielsen [29] and Mizuno et al. [30] (Figures 2a and 2b). In general, D1 and D2 inhibition measures presynaptic inhibition elicited by peripheral nerve stimulation while $\mathrm{FN}$ facilitation is a reflection of the amount of ongoing presynaptic inhibition of $\mathrm{FN}$ la afferents [29]. Disynaptic reciprocal inhibition initially described by Crone et al. [31] was also assessed to evaluate the effect that the antagonist muscle nerves have on the soleus la inhibitory interneurons (Figure 2c).

\section{Conditioning femoral nerve} simulation (FNS) of the soleus H-reflex FNS was applied to the skin over the femoral nerve in the femoral triangle using a $10 \mathrm{~mm}$

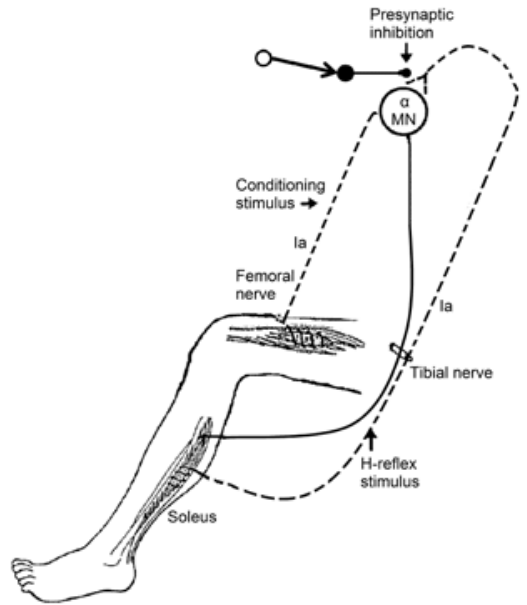

Figure 2a. Heteronymous la presynaptic inhibition of la afferents elicited by a condition stimulus to the femoral nerve. Figure illustrates the spinal circuit during which femoral nerve stimulation at $1.1 \mathrm{x}$ motor threshold intensity delivered after tibial nerve stimulation elicits monosynaptic excitation of the soleus motoneurons. The mean ratio's between $H_{\text {conditioned }} / M_{\max }$ relative to the $H_{\text {mend }} / M_{\text {rax }}$ reflex amplitude were compared among the experiment phases. A decrease in the mean $\mathrm{H}_{\text {unconditoned }}$ ' $M$ would indicate an increase in la presynaptic inhibition.

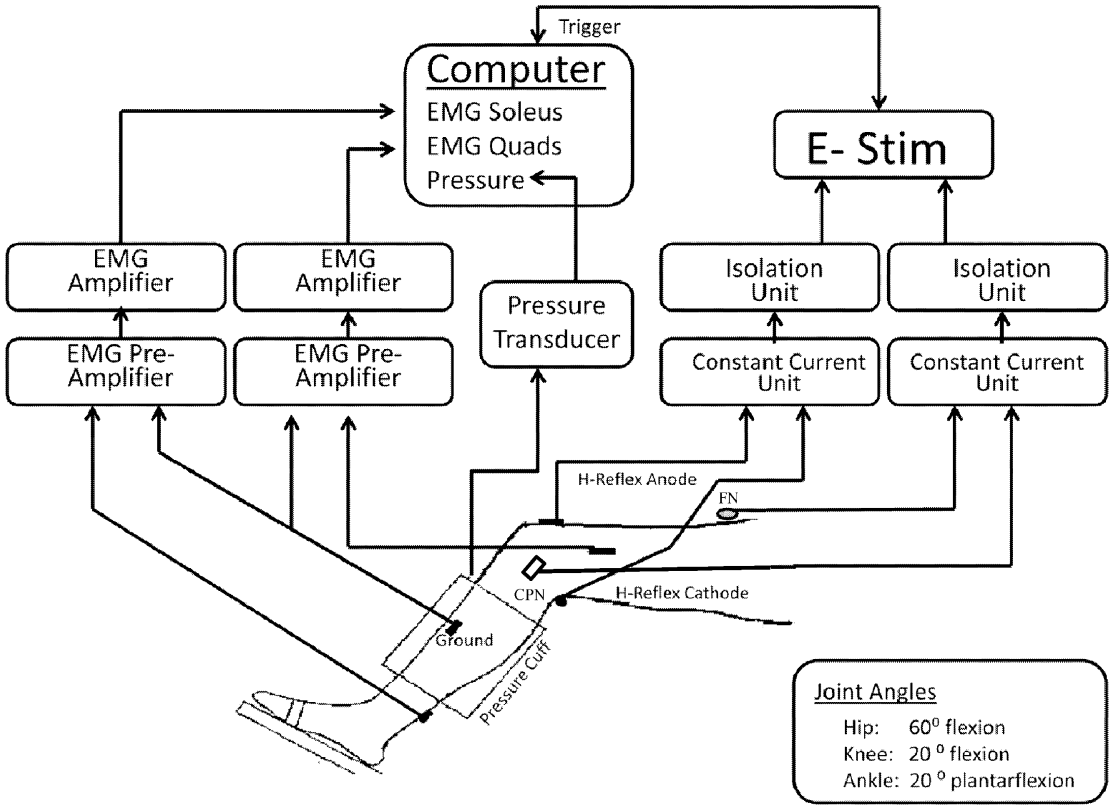

Figure 1. Experimental set-up. EMG monitoring electrodes and wiring schematic are not shown for the tibialis anterior muscle.

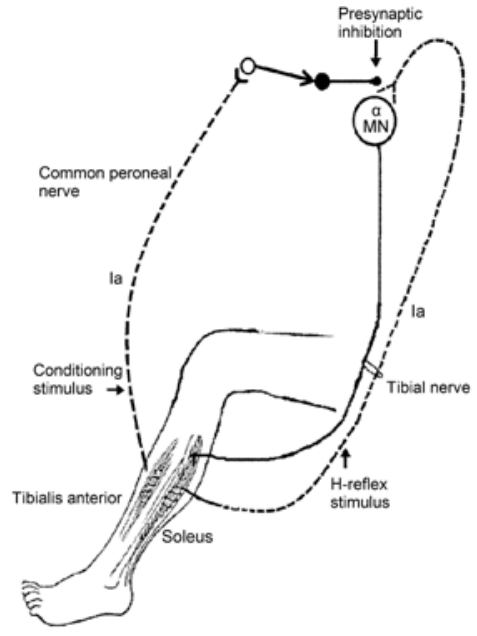

Figure $2 \mathrm{~b}$. Homonymous presynaptic inhibition of la afferents elicited by a conditioning stimulus to the common peroneal nerve. Figure illustrates the spinal circuit during which a $1.1 \mathrm{x}$ motor threshold conditioning stimulus was applied at interstimulus intervals of $10 \mathrm{~ms}$ and 25 ms for D1 inhibition and at $50 \mathrm{~ms}, 75 \mathrm{~ms}$ and $100 \mathrm{~ms}$ for D2 inhibition. The level of homonymous presynapitc inhibition was measured by calculating the change in the mean ratio's between $\mathrm{H}_{\text {conditioned }}$ $\mathrm{M}_{\text {max }}$ relative to the $U_{\text {nncontiod }} / M_{\text {max }}$ reflex amplitude among the experiment phases.

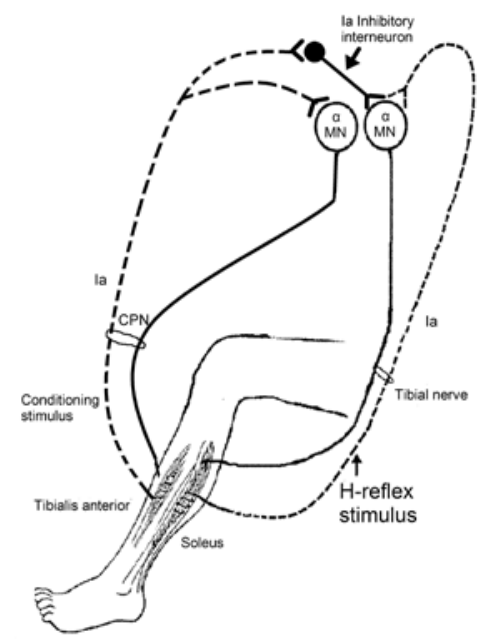

Figure 2c. Disynaptic Reciprocal inhibition (DSRI). Figure illustrates the spinal circuit of DSRI exerted on ankle plantar flexors following a $1 \mathrm{~ms}$ common peroneal nerve conditioning stimulus at $1.1 \mathrm{x}$ motor threshold. DSRI involves the la inhibitory interneuron that is exerted at a postsynaptic level. Conditioning stimuli were given at 1,3 and $10 \mathrm{~ms}$ before tibial nerve stimulation eliciting the $\mathrm{H}$-reflex. DSRI was measured by calculating the change in the mean ratio's between $\mathrm{H}_{\text {conditioned }} / \mathrm{M}_{\max }$ relative to the $U_{\text {uncondtioned }} / \mathrm{M}_{\max }$ reflex amplitude among the experiment phases. 
monopolar surface electrode. A $3 \times 3 \mathrm{~cm}$ anodal sponge fixed to the posterior proximal thigh served as the reference electrode. A bipolar recording electrode (10 $\mathrm{mm}$ discs) was placed on the skin over the belly of the vastus lateralis muscle $6-8 \mathrm{~cm}$ proximal and lateral to the patella to monitor myoelectric activity from the quadriceps muscle.

FNS consisted of a $1 \mathrm{~ms}$ rectangular pulse given at a frequency of $0.17 \mathrm{~Hz}$. Stimulus strength was adjusted to $1.1 \mathrm{x}$ the quadriceps motor threshold (MT) and the afferent volley was used as the conditioning stimulus that facilitated $\mathrm{H}_{\text {unconditioned }}$. This facilitation occurred between a conditioning-test interval of -3.0 to $-7.5 \mathrm{~ms}$. The negative conditioning-test interstimulus intervals designate that the conditioning simulation was applied after the test stimulation. The delay was adjusted according to the height of the subject until the H-reflex was consistently larger than $\mathrm{H}_{\text {unconditioned' }}$ as observed on the digital storage oscilloscope. Hultborn et al. [15] have shown that during the first $0.5 \mathrm{~ms}$ the heteronymous la facilitation is only mediated through a monosynaptic pathway and not contaminated by other input. la presynaptic inhibition was measured by calculating the change in the mean ratio's between $\mathrm{H}_{\text {conditioned }} / \mathrm{M}_{\max }$ relative to the $\mathrm{H}_{\text {unconditioned }} / \mathrm{M}_{\max }$ reflex amplitudes among the experimental phases. Twenty-five $\mathrm{H}_{\text {conditioned }}$ reflexes were elicited and averaged in each phase. $A$ decrease in the mean $\mathrm{H}_{\text {conditioned }} / \mathrm{M}_{\max }$ would indicate an increase in la presynaptic inhibition.

Before reaching any conclusions that a change in H-reflex facilitation was due to ongoing presynaptic inhibition of la afferents mediating the conditioning volley, a change in the reflex recruitment gain must be ruled out [32]. To ensure that any effects were not due to these changes D1 and D2 inhibition was also analyzed. FNS and D1/D2 inhibition provide autonomous information concerning presynaptic inhibition and they assist in excluding changes in recruitment gain as a cause for changes in $\mathrm{H}$-reflex size [33,34]. In addition, all experiments were performed in a reclined position at rest [35] and the M-wave amplitude was closely monitored throughout the experiment [26]. Any observable change
( \pm 1 SD) in its amplitude or configuration resulted in data omission.

CPN conditioning stimulus of the Soleus H-reflex

A bipolar electrode (10 $\mathrm{mm}$ disks) was placed on the skin of the fibular head over the CPN. This stimulus was used as a conditioning stimulus to evoke reciprocal, D1 and D2 presynaptic inhibition of the soleus muscle. The optimal stimulation site was selected based on the following criteria: the Tibialis Anterior (TA) motor threshold was lower than that of the peroneal muscles and at increased levels of stimulation intensities, ankle eversion and peroneal muscle activity were absent Stimulation to the CPN was delivered with a $1 \mathrm{~ms}$ constant current pulse at $1.1 \times \mathrm{TA}$ MT. H-reflexes were then elicited following conditioning stimulation to the CPN at eight predetermined interstimulus delays. The delays were set at 1, 3, $510,25,50,75$ and 100 ms and randomly delivered. For each interstimulus delay, peak to peak amplitudes of $5 \mathrm{H} / \mathrm{M}_{\max }$ ratios were averaged and expressed as a percent of $\mathrm{H}_{\text {unconditioned }} / \mathrm{M}_{\max }$

Throughout all phases of this experiment $\mathrm{H}_{\text {unconditioned }}$ amplitudes were randomly checked to ensure it remained unchanged. If $\mathrm{H}_{\mathrm{H}}$ amplitude increased or decreased, tibial nerve stimulation intensity was adjusted back to original $\mathrm{H}_{\text {baseline }}$ value [28].

\section{Statistical analysis}

The StigmaStat version 2.0 statistical software program was used for all data analysis. $\mathrm{H}_{\text {conditioned }}$ reflex amplitudes were averaged for the prepressure phase and for each of the two testphases (pressure and post-pressure). Peak-topeak amplitudes were then measured.

Friedman repeated measures analysis of variance on ranks tests were used to analyze the change from pre-pressure values in the average $\mathrm{H}_{\text {conditioned }}$ reflex amplitudes during and after pressure application. Parametric testing was not performed because the data was not normally distributed. Dunnett's multiple comparison tests were used when significant $F$ values were found. The level of significance for all post hoc tests was designated $p<0.05$.

\section{Results}

Statistical analysis was performed on 19 of the 38 initial subjects, ranging in age from 22-34 years old (mean=26.8, SD=3.4). Inclusion criteria were: 1) Subject had a consistent facilitation of $\mathrm{H}_{\text {unconditioned }}$ with the conditioning stimulus, 2) No change in soleus, TA and/or quadriceps M-wave configurations, and 3) a consistent $\mathrm{H}_{\text {unconditioned }}$ that could be re-established before, during and after pressure application. Figure 3 shows a typical H-reflex from a representative subject.

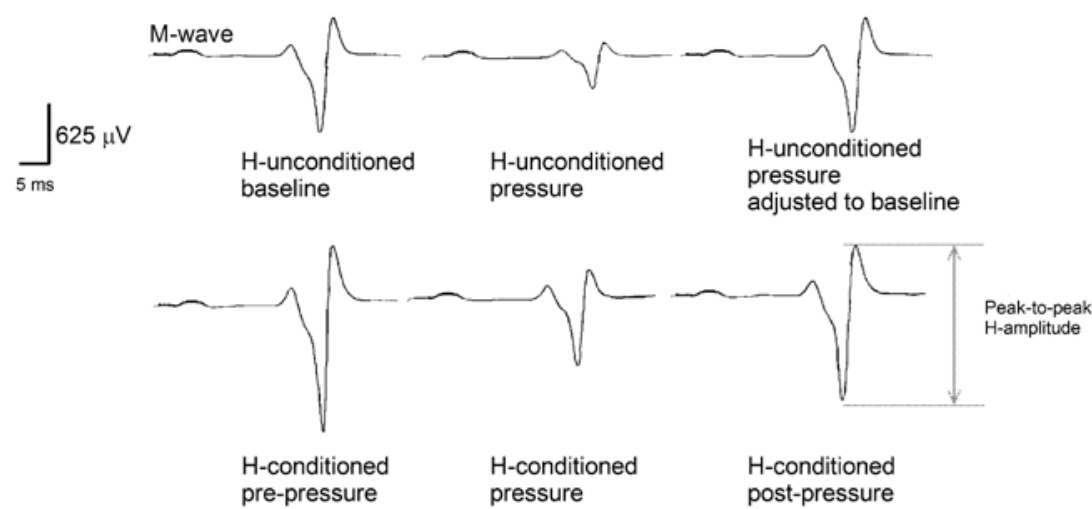

Figure 3. Demonstration of the H-reflex peak-to-peak amplitude changes for heteronymous la presynaptic inhibition that takes place throughout the experiment in a typical subject. Note the pre-pressure $\mathrm{H}$-reflex facilitation from baseline levels that results from femoral nerve stimulation and the inhibition that occurs in the conditioned $\mathrm{H}$-reflex during $\mathrm{CP}$ when compared to pre-pressure values. Each line represents an average of 20 recordings. 
Nineteen subjects were omitted from the analysis because they failed to meet inclusion criteria. When $\mathrm{CP}$ was applied, $\mathrm{H}$ amplitude dropped dramatically in every subject (55\% mean decrease; SD 27.45). To accommodate for this significant drop, $\mathrm{H}_{\text {unconditioned }}$ was increased to restore it to initial $\mathrm{H}_{\text {baseline }}$ levels [28]. The re-establishment of $\mathrm{H}_{\text {unconditioned }}$ proved challenging and was the primary criteria for excluding subjects from the study $(n=11)$. The other eight subject's data were omitted due to changes in reflex configurations of the $\mathrm{M}$ wave, $\mathrm{H}$-reflex or both when the air splint was inflated.

When compared to pre-pressure values, a significant $(p=0.013)$ mean decrease of $12.5 \%$ was observed in FNS during CP application (Figure 4). This decrease in the $\mathrm{H}_{\text {conditioned }}$ reflex amplitude is believed to be due to an increase in la Presynaptic Inhibition (laPI) [15]. Figure 5 shows the individual data from the 19 subjects whose date were analyzed. As can be seen from the figure, 15 subjects exhibited an increase in laPI during the pressure phase. Subjects 2 , 5 and 13 showed an increase in the $\mathrm{H}$ reflex amplitude, indicating large decreases in laPI of $98 \%, 44 \%$, and $28 \%$ respectively. Subject 19 was the only one who did not show any change in laPI. If the three subjects who showed decreases in laPI were treated as outliers and had their results excluded from data analysis, laPI would have had a mean increase of $26 \%$ when compared to pre-pressure levels. Because their $\mathrm{H}_{\text {unconditioned }}$ values dramatically decreased similarly to the other 16 subjects when CP was initially applied, it was considered the decrease in FNS observed was an accurate representation of their response and therefore their data were included in the analysis.

Post-pressure data was not significantly different from pre-pressure levels. Most subjects showed a decrease in laPI toward baseline pre-pressure levels. Individual responses however varied. For example, five subjects showed a phase reversal demonstrating a substantial decrease in laPI above baseline levels (subjects 3, 6, 8, 14, 19) and in one subject (subject 18) laPI increased beyond pressure levels (Figure 5).

Figure 6 illustrates the DSRI, D1 and D2 inhibition between pressure and pre-pressure measurements that were observed at CPN conditioning interstimulus intervals of $1,3,5$, 10, 25, 4075 and $100 \mathrm{~ms}$. As can be seen from the figure, $\mathrm{CP}$ caused a slight mean increase in

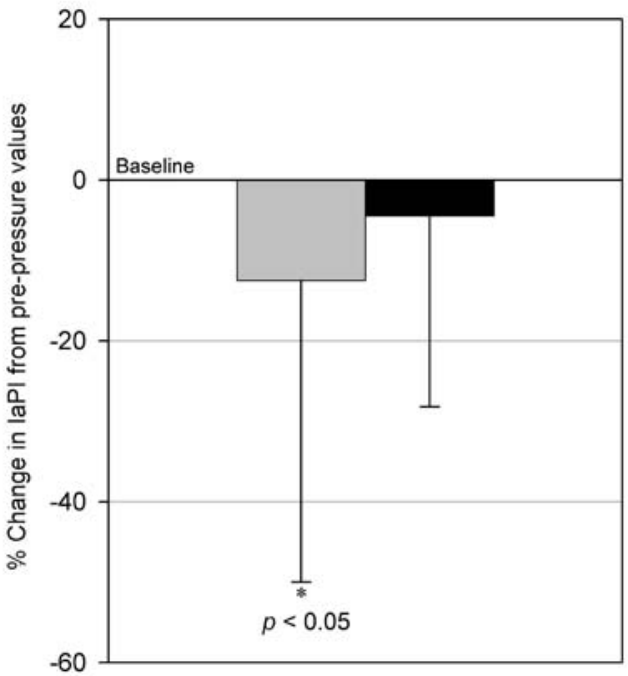

Figure 4. Mean percent change $(n=19)$ in the $\mathrm{H}_{\text {conditioned }}$ reflex during CP after FNS. A mean $12.5 \%$ decrease was observed. Standard deviations are also shown. Decreases in the $\mathrm{H}$ reflex amplitudes represent an increase in laPI. $\left(0 \%=\mathrm{H}_{\text {conditioned }}\right.$ pre-pressure values $)=$ pressure, $\boldsymbol{W}=$ post-pressure

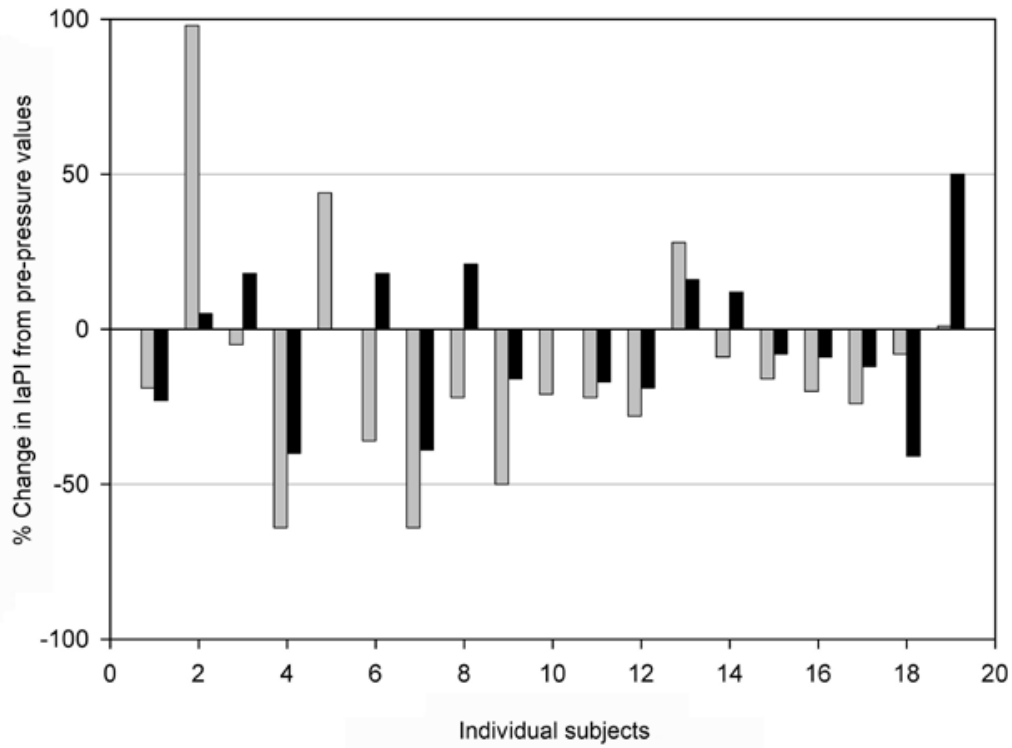

Figure 5. Heteronmous la presynaptic inhibition individual subject data showing the percent change in the $\mathrm{H}_{\text {conditioned }}$ reflex amplitudes during and after pressure inhibition when compared to pre-pressure values. Note: subjects 2, 5, and 13 exhibited a decrease in presynaptic inhibition as shown by an increase in the $\mathrm{H}_{\text {conditioned }}$ reflex amplitudes. Each bar represents an average of 20 recordings. $\left(0 \%=\mathrm{H}_{\text {conditioned }}\right.$ pre-

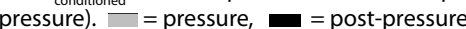


one minute after pressure release returned to baseline pre-pressure levels in all subjects ( $p>0.05$ ). This rapid return to pre-pressure levels is likely due to CP's short-lasting effect $[6,7]$.

\section{Discussion}

The main finding of this study showed that $\mathrm{CP}$ to the calf significantly decreased soleus $\mathrm{H}$-reflex heteronymous la facilitation when compared to pre-pressure values. Two distinct methods involving conditioning the soleus H-reflex, FNS and D1/D2 inhibition were used to assess presynaptic inhibition. FNS reflects the level of ongoing presynaptic inhibition of the la afferents onto motoneurons while D1/ D2 inhibition gives an indication of presynaptic inhibition elicited by peripheral nerve stimulation. Additionally, the two techniques provide autonomous information about presynaptic inhibition that help in determining if changes in the recruitment gain within the soleus motoneuron pool is responsible for any of the observable changes in H-reflex amplitude [32]. For example, a change in the level of presynaptic inhibition should induce similar changes in the amplitude of the conditioned $\mathrm{H}$-reflexes recorded with the two methods as long as the conditioning stimulus elicits a monosynaptic excitatory postsynaptic potential of constant size in primary afferent depolarization interneurons (PAD) or motor neurons. Thus, an increase in presynaptic inhibition would result in a decrease in the amplitude of the conditioned $\mathrm{H}$-reflex for both D1/D2 inhibition and FNS. Since this was the case, it was believed that $C P$ caused a true increase in presynaptic inhibition and not a decrease in reflex gain.

Previous studies investigating $\mathrm{CP}$ around the calf suggested that muscle stretch is a likely cause [5-7]. The compressive forces created by the air splint would seemingly cause a minimal amount of stretch to all of the muscle fibers beneath the splint. Studies have shown that small amplitude passive stretches to the soleus causes significant reductions in alpha MNRE [36,37]. Guissard et al. further showed that this decrease in MNRE following small passive stretch was due to an increase in la presynaptic inhibition [21]. If muscle

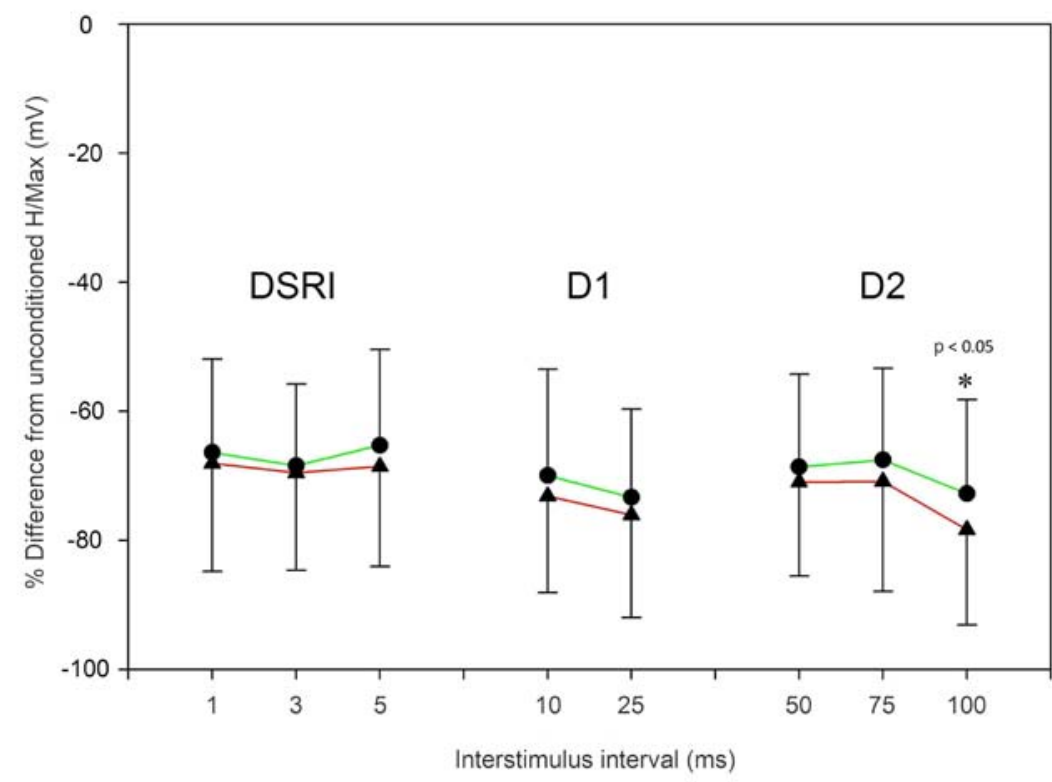

Figure 6. Mean percent ratio change $(n=19)$ in the $\mathrm{H}_{\text {conditioned }}$ reflexes following stimulation to the common peroneal nerve at interstimulus intervals of $1,3,5,10,25,50,75,100 \mathrm{~ms}$. Interstimulus intervals represent Disynaptic Reciprocal Inhibition $(1,3,5), D 1(10,25)$ and D2 inhibition $(50,75,100 \mathrm{~ms})$ respectively. Interstimulus interval at $100 \mathrm{~ms}$ was the only significant interstimulus interval $(p<0.05)$. SDs are also shown.

stretch is the novel stimulus that initiates the increase in laPI, group II muscle afferents are likely responsible. They have been shown to discharge as long as muscle stretch is sustained [38,39], to have a low threshold of activation [38], to inhibit extensor muscles [40,41], and to generate primary afferent depolarization by the activation of GABAergic interneurons [42].

Cutaneous receptors that specifically sense stretch and pressure (Merkel and Ruffini receptors) also have been indicated in increasing laPI during pressure $[23,43]$. These receptors are stimulated by lightly stretching the skin [44], continue to discharge for the entire duration of stimulus [45], and may also have a role in modulating presynaptic inhibition of la afferents $[23,42,43]$. How much they function in inhibiting MNRE through a presynaptic mechanism is unknown. Further research is needed to assess the effect of these cutaneous receptors on MNRE when $\mathrm{CP}$ is applied to a limb.

Descending input onto spinal motoneurons from cortical and brain stem areas may also have contributed to the lowering of $\mathrm{H}$-reflex amplitudes observed in this study. It is well known that these descending pathways converge onto dorsal horn neurons and have a gating and filtering affect on PAD through a presynaptic mechanism [46-48]. Recent studies have shown that short-latency afferent inhibition is mediated though a spinal rather than a cortical circuit in the lower extremity $[49,50]$. This aspect coupled with the finding that CP significantly decreased the soleus H-reflex in people with complete traumatic spinal cord injury [7] strongly suggests that any influence from supraspinal systems would be negligible.

Air splint inflation dramatically decreased the unconditioned $\mathrm{H}$-reflex amplitude in every subject tested in this investigation. Sometimes $(n=11)$, the extent of the inhibition was so significant that $\mathrm{H}$-baseline levels could not be re-established. For $\mathrm{CP}$ to inhibit the $\mathrm{H}$-reflex to this level, a greater than $12.5 \%$ increase in laPI would be necessary. In addition, three subjects displayed decreases in laPI during pressure, yet their unconditioned $\mathrm{H}$-reflex was strongly inhibited. If laPI was the sole mechanism of 
neuronal control during CP application, all subjects would have shown inhibition of the conditioned H-reflex and to a much greater extent. Thus, the increase in laPI observed in this study cannot fully explain the dramatic decrease in the unconditioned $\mathrm{H}$-reflex during the application of CP.

It is a difficult task to hypothesize what other spinal mechanisms may participate in lowering MNRE besides la presynaptic inhibition. Previous studies show that tissue ischemia [6-8] and changes to the input/output properties of the reflex arc are not responsible [5]. Ib non-reciprocal inhibition is unlikely involved because the soleus tendon receptors are not sensitive enough to detect the forces produced by the minimal passive stretch created by the air splint [51,52]. Finally, CP did not affect DSRI. These findings imply that another mechanism, possibly musculo-skeletal in origin, may be involved.

Leukel et al. [5] conducted a study that investigated the effect pressure applied around the calf had on spinal cord reflexes similar to the methods used in this study. The only difference was that pressures of $240-250 \mathrm{mmHg}$ were used compared with the $40-45 \mathrm{mmHg}$ used in our study. Leukel et al. [5] showed a significant $\mathrm{H}$-reflex depression similar to what we observed. Since CP did not cause any change in the input/output properties of the reflex arc, they hypothesized, that the viscouselastic components of the musculo-tendonous junction distal to the cuff were responsible for the decrease in reflex amplitude. They argued that the inflated cuff "clamps" the muscle thereby preventing the underlying tissue from naturally moving. It was further shown that this damping effect occurs only when the muscle tensions were low. The decrease in $\mathrm{H}$-reflex amplitude observed in this study may have been mediated through a similar mechanism caused by air splint compression. Whether the low pressures used in this study were sufficient to induce the mechanical change necessary to affect $\mathrm{H}$-reflex amplitude still requires further investigation.

Finally, little attention has been given to the effects that group III and IV muscle afferents have on the motoneuron pool. Usually these afferents are concerned with relaying information to the central nervous system regarding the metabolic state and mechanical activity of exercising muscle [53-55]. Substantial evidence exists, however, that group III and IV muscle afferents also play an important role in regulating spinal motoneuron excitability [56-60]. The discharge properties of these afferents were shown to affect the motoneurons in a flexor-reflex pattern of excitation; increasing excitability of ipsilateral flexors and inhibition of ipsilateral extensors [59]. It is quite possible that CP may elicit group III and IV afferents that inhibit the soleus muscle motoneurons. Evidence demonstrates that pressure application [59] and muscle stretch $[59,60]$ activate these afferents. Whether CP reaches the critical level to elicit these afferents remains speculative and requires further research. It does, however, provide an additional explanation for the dramatic decrease observed in the soleus $\mathrm{H}$-reflex amplitude during $\mathrm{CP}$ application to the calf.

\section{Clinical implications}

Results from previous pressure studies applied by an air splint to the calf showed that MNRE decreased in all subjects and patients tested $[6,7]$. Due to these results, these authors advocate using $\mathrm{CP}$ in treating hypertonia resulting from upper motor neuron syndrome. It is always an arduous task for therapists to choose a therapeutic modality that is efficacious without knowing how it works. The results of this study were unable to detect fully how CP lowers MNRE except that la presynaptic inhibition plays a small role. Clinicians therefore should be aware of the many spinal and peripheral mechanisms that $\mathrm{CP}$ may use in modulating MNRE and routinely monitor their treatment effects to assure if the functional outcomes in their patients are what was expected. This is especially true when muscle contraction and movement are a condition $[3,5]$.

\section{Summary}

The unconditioned H-reflex amplitude dramatically decreased in every subject during pressure application. Previous research conducted on people with complete traumatic spinal cord injury has suggested that this decrease in H-reflex amplitude was spinal in origin [7]. In an attempt to elucidate the spinal mechanism that is responsible for this inhibition, two segmental inhibitory mechanisms were investigated: disynaptic reciprocal inhibition and la presynaptic inhibition. Results showed that la presynaptic inhibition increased in $79 \%$ of our subjects but only modestly. No change was seen in DSRI. It was concluded that laPI contributed to the H-reflex inhibition during $\mathrm{CP}$ but could not account for the total observed reflex inhibition. Additional mechanism(s) of control must also be involved [1]. The possible mechanisms that may participate are discussed.

\section{Acknowledgments}

This project was supported in part by the Graduate Programs Fund, College of, Human Science and Services, University of Rhode Island.

\section{Abbreviations}

\begin{tabular}{|c|c|}
\hline $\mathrm{CP}$ & - Circumferential Pressure \\
\hline CPN & - Common Peroneal Nerve \\
\hline DSRI & - Disynaptic Reciprocal Inhibition \\
\hline FN & - Femoral Nerve \\
\hline FNS & - Femoral Nerve Stimulation \\
\hline EMG & - Electromyography \\
\hline $\mathrm{H}_{\text {baseline }}$ & $\begin{array}{l}\text { - Unconditioned H-reflex }(25 \% \text { of } \\
\left.M_{\max }\right)\end{array}$ \\
\hline $\mathrm{H}_{\max }$ & - Maximal H-Reflex \\
\hline $\mathrm{H}_{\text {conditioned }}$ & - Conditioned H-Reflex \\
\hline $\mathrm{H}_{\text {unconditioned }}$ & - Unconditioned H-reflex \\
\hline H-Reflex & - Hoffmann Reflex \\
\hline $\mathrm{laPI}$ & - la Presynaptic Inhibition \\
\hline$M_{\max }$ & - Maximal Motor response \\
\hline MNRE & - Motoneuron Reflex Excitability \\
\hline PAD & - Primary Afferent Depolarization \\
\hline $\mathrm{SCl}$ & - Spinal Cord Injury \\
\hline SD & - Standard Deviation \\
\hline TA & - Tibialis Anterior muscle \\
\hline
\end{tabular}


[1] Agostinucci J., The effects of circumferential pressure on the soleus muscle F-wave in healthy subjects, J. Electromyiogr. Kinesiol., 2012, 22, 223-227

[2] Agostinucci J., Inhibitory effects of circumferential pressure on flexor carpi radialis $\mathrm{H}$-reflex in adults with neurological deficits, Percept. Mot. Skills, 2010, 110, 89-103

[3] Agostinucci J., Effect of air-splint pressure on the soleus stretch reflex during a voluntary ramp plantar flexion. Neurophysiol., 2010, 12, 3138

[4] Agostinucci J., Holmberg A., Mushen M., Plisko J., Gofman M., The effects of circumferential air-splint pressure on flexor carpi radialis $\mathrm{H}$-reflex in subjects without neurological deficits, Percept. Mot. Skills, 2006, 103, 565-579

[5] Leukel C., Lundbye-Jensen J., Gruber M, Zuur A.T., Goohofer A., Taube W., Short-term pressure induced suppression of the short-latency response: a new methodology for investigating stretch reflexes, J. Appl. Physiol., 2009, 107, 1051-1058

[6] Robichaud J. A., Agostinucci J., VanderLinden D. W., Effect of airsplint application on soleus muscle motoneuron reflex excitabililty in nondisabled subjects and subjects with cerebrovascular accidents, Phys. Ther., 1992, 72, 176-185

[7] Robichaud J. A., Agostinucci J., Air-splint pressure effect on soleus muscle alpha motoneuron reflex excitability in subjects with spinal cord injury, Arch. Phys. Med. Rehabil., 1996, 77, 778-782

[8] Robichaud J. A., Brunt D., Effect of circumferential pressure on response parameters during ballistic ankle plantar flexion in healthy subjects, Percept. Mot. Skills, 1994, 78, 427-434

[9] Enriquez-Denton M., Nielsen J., Perreault M. C., Morita H., Petersen N., Hultborn H., Presynaptic control of transmission along the pathway mediating disynaptic reciprocal inhibition in the cat, J. Physiol., 2000, 526, 23-637

[10] Gottlieb G. L., Myklbust B. M., Penn R. D., Agarwal G. C., Reciprocal Excitation of Muscle Antagonists by the primary afferent pathway, Exp. Brain. Res., 1982, 46, 454-456

[11] Levin M., Chapman C. E., Inhibitory and facillitatory effects from the peroneal nerve onto the soleus $\mathrm{H}$-reflex in normal and spinal man, Electroencephalo. Clin. Neurophysiol.,1987, 67, 468-478

[12] Milanov I. G., Flexor reflex for assessment of common interneuron activity in spasticity, Electromyogr. Clin. Neurophysiol., 1992, 32, 621629

[13] Abbruzzese M., Reni L., Minatel C., Favale E., Presynaptic and postsynaptic mechanisms underlying $\mathrm{H}$-reflex changes produced by a selective voluntary contraction, Muscle Nerve, 1998, 21, 439-453

[14] Calancie B., Broton J. G., Klose K. J., Traad M., Difini J., Ayyar D. R., Evidence that alterations in presynaptic inhibition contribute to segmental hypo- and hyperexcitabililty after spinal cord injury in man, Electroecphalogr. Clin. Neurophysiol., 1993, 89, 177-186

[15] Hultborn H., Meunier S., Morin M. C., Pierrot-Deseilligny E., Assessing changes in presynaptic inhibition of la fibres: a study in man and the cat, J. Physiol., 1987, 389, 757-772.
[16] lles J. F., Roberts R. C., Inhibition of monosynaptic reflexes in human lower limb. J. Physiol., 1987, 108, 450-462

[17] Inghilleri M., Lorenzano C., Gilio F., Pedace F., Romeo S., Manfredi M., et al. la presynaptic inhibition after muscle twitch in the arm, Muscle Nerve, 2000, 23, 748-752

[18] Kohn A. F., Floeter M. K., Hallett M., Presynaptic inhibition compared with homosynaptic depression as an explanation for soleus $\mathrm{H}$-reflex depression in humans, Exp. Brain Res., 1987, 116, 375-380

[19] Morin C., Pierrot-Deseilligny E., Hultborn H., Evidence for presynaptic inhibition of muscle spindle la afferents in man, Neurosci. Lett., 1984, 44, 137-142

[20] Nielsen J., Petersen N., Is presynaptic inhibition distributed to corticospinal fibers in man?, J. Physiol., 1994, 477, 147-158

[21] Guissard N., Duchateau J., Hainaut K., Mechanisms of decreased motoneuron excitation during passive muscle stretching, Exp. Brain Res., 2001, 137, 163-169

[22] Aimonetti J. M., Vedel J.P., Schmied A., Pagni S., Inhibition versus facilitation of the reflex responsiveness of identified wrist extensor motor units by antagonist flexor afferent inputs in humans, Exp. Brain Res., 2000, 133, 391-401

[23] Nakashim K., Rothwell J. C., Day B. L., Thompson P.D., Marsden C. D., Cutaneous Effects of Presynaptic Inhibition of flexor la afferents in the human forearm, J. Physiol., 1990, 426, 369-380

[24] Rudomin P., Schmidt R. F., A presynaptic inhibition in the vertebrate spinal cord revisited, Exp. Brain Res., 1999, 129, 1-37

[25] Eke-Okoro S. T., The H-reflex studied in the presence of alcohol, aspirin, caffeine, force, and fatigue, Electromyogr. Clin. Neurophysiol., $1982,22,579-589$

[26] Knikou M., The H-reflex as a probe: Pathways and pitfalls, J. Neurosci. Methods, 2008, 171,1-12

[27] Palmieri R. M., Ingersoll C. D., Hoffman M. A., The Hoffman reflex: methodologic considerations and applications for use in sports medicine and athletic training research, J. Athl. Train., 2004, 39, 268277

[28] Crone C., Hultborn H., Mazieres L., Morin C., Nielsen J., PierrotDeseilligny E., Sensitivity of monosynaptic test reflexes to facilitation and inhibition as a function of the test reflex size: a study in man and the cat, Exp. Brain Res., 1990, 81: 35-45

[29] Lundbye-Jensen J., Nielsen J. B., Immobilization induces changes in presynaptic control of group la afferents in healthy humans, J. Physiol., 2008, 586, 4121-4135

[30] Mizuno Y., Tanaka R., Yanagisawa N., Reciprocal group I inhibition on triceps surae motoneurons in man, J. Neurophysiol., 1971, 34, 10101017

[31] Crone C., Hultborn H., Jespersen B., Nielsen J., Reciprocal la inhibition between ankle flexors and extensors in man, J. Physiol., 1987, 389, 163-185

[32] Kernell D, Hultborn $H$. Synaptic effects on recruitment gain: a mechanism of importance for the input-output relations of motoneurone pools?, Brain Res., 1990, 507, 76-179 
[33] Nielsen J., Kagamihara Y., Differential projection of the sural nerve to early and late recruited human tibialis anterior motor units: change of recruitment gain, Acta. Physiol. Scand., 1993, 147, 385401

[34] Nielsen J., Kagamihara Y., The regulation of presynaptic inhibition during co-contraction of antagonistic muscles in man, J. Physiol., 1993, 464, 575-593

[35] Pierrot-Deseilligny E., Assessing changes in presynaptic inhibition of la afferents during movement in humans, J. Neurosci. Methods, 1997, 74, 189-199

[36] Pinniger G. J., Nordlund M., Steele J. R., Cresswell A. G., H-reflex modulation during passive lengthening and shortening of the human triceps surae, J. Physiol., 2001, 534, 913-923

[37] Romano C., Schieppati M., Reflex excitability of human soleus motoneurons during voluntary shortening or lengthening contractions, J. Physiol., 1987, 390, 271-284

[38] Carpenter D. O., Henneman E., A relation between the threshold of stretch receptors in skeletal muscle and the diameter of their axons, J. Neurophysiol., 1966, 29, 353-368

[39] Somjen G., Sensory coding in the mammalian nervous system, Plenum Publishing Corp., New York, 1975

[40]Lundberg A., Malmgren K., Schomburg E. D., Reflex pathways from group II muscle afferents 2: functional characteristics of reflex pathways to alpha motoneurons, Exp. Brain Res., 1987, 65, 282-293

[41] Ushiba J., Masakado Y., Komune Y., Muraoka Y., Chino N., Tomita Y., Changes of reflex size in upper limbs using wrist splint in hemiplegic patients, Electromyogr. Clin. Neurophysiol., 2004, 44, 175-182

[42] Rudomin P., In search of lost presynaptic inhibition, Exp. Brain Res., 2009, 196, 139-151

[43] lles J.F., Reciprocal inhibition during agonist and antagonist contraction, Exp. Brain Res., 1986, 62, 212-214

[44] Chambers K. H., Monika A., Duering V., Iggo, A., The structure and function of the slowly adapting type II mechanoreceptor in hairy skin, Q. J. Exp. Physiol. Cogn. Med. Sci., 1972, 57, 417-445

[45] Boulais N., Misery L., The epidermis: a sensory tissue, Eur. J. Dermatol., 2008, 18, 119-127

[46] Jacobs J. V., Horak F. B., Review: Cortical control of postural responses, J. Neural Transm., 2007, 114, 1339-1348
[47] Brouwer B, Ashby P., Corticospinal projections to lower limb motoneurons in man, Exp. Brain Res., 1992, 89, 649-654

[48] Wall, P. D., The laminar organization of dorsal horn and effects of descending impulses, J. Physiol., 1967, 403-423

[49] Roy F. D, Gorassini M. A., Peripheral sensory activation of cortical circuits in the leg motor cortex of man, J. Physiol., 2008, 4091-4105

[50] Grey M. J., Ladouceur M., Andersen J. B., Nielsen J. B., Sinkjaer T., Group II muscle afferents probably contribute to the medium latency soleus stretch reflex during walking in humans, J. Physiol., 2001, 25933

[51] Jami L., Golgi tendon organs in mammalian skeletal muscle: functional properties and central actions, Physiol. Rev., 1992, 72, 623-666

[52] Gregory J. E., Proske U., The responses of Golgi tendon organs to stimulation of different combinations of motor units, J. Physiol., London, 1979, 295, 251-262.

[53] Adreani C. M., Hill J. M., Kaufman M. P., Responses of group III and IV muscle afferents to dynamic exercise, J. Appl. Physiol., 1997, 82, 18111117

[54] Kaufman M. P., Hayes S. G., The exercise pressor reflex, Clin. Auton. Res., 2000, 12, 429-439

[55] Mitchell J. H., Kaufman M. P., Iwamoto G. A., The exercise pressor reflex: its cardiovascular effects, afferent mechanisms and central pathways, Annu. Rev. Physiol., 1983, 45, 229-242

[56] Garland S. J., Kaufman M. P., Role of muscle afferents in the inhibition of motoneurons during fatigue, In: Fatigue: neural and muscular mechanism, Gandevia S.C., Enoka R.M., McComas A.J., Stuart D.G., Thomas C.K. (Eds.), Plenum Press, New York, 1995

[57] Martin P. G., Smith J. L., Butler J. E., Gandevia S. C., Taylor J. L., Fatiguesensitive afferents inhibit extensor but not flexor motoneurons in humans, J. Neurosci., 2006, 26, 4796-4802

[58] Martin P. G., Weerakkody N., Gandevia S. C., Talor J. L., Group III and IV muscle afferents differentially affect the motor cortex and motoneurons in human, J. Physiol., 2008, 586, 1277-1289

[59] Kniffki D. D., Schomburg E. D., Steffens H., Synaptic effects from chemically activated fine muscle afferents upon a-motoneurones in decerebrate and spinal cats, Brain Res., 1981, 206, 361-370

[60] Abrahams V. C., Lynn B., Richmond F. J., Organization and sensory properties of small myelinated fibres in the dorsal cervical rami of the cat, J. Physiol., 1984, 347, 177-187 